\title{
An Assessment Of Birth Preparedness And Complication Readiness In Antenatal Women In Umuahia North Local Government Area, Abia State, Nigeria.
}

\author{
U. C Emma-Ukaegbu ${ }^{1}$, H I Nwokeukwu ${ }^{1}$, B.S.C Uzochukwu ${ }^{2}$. \\ 1. Department of Community Medicine Federal Medical Center, Umuahia. Abia state, Nigeria \\ 2. Department of Community Medicine University of Nigeria Teaching Hospital. \\ Ituku Ozallah, Enugu. Enugu state, Nigeria
}

\begin{abstract}
Background: Birth-preparedness and complication readiness (BP/CR) is a key strategy in safe motherhood Programmes which mitigate delays that could lead to increased maternal mortality. BP/CR is not effectively utilized in Nigeria. This study assessed the level of BP/CR and associated factors amongst women receiving antenatal care in Umuahia North L.G.A of Abia state Nigeria.

Objectives: To assess the awareness of danger signs of obstetric complications and to identify associated factors of pregnant women receiving antenatal care in public and private health care facilities in Umuahia North L.G.A.

Methodology: A descriptive cross sectional study. Interviewer administered questionnaires were used to obtain data. Data was analysed using SPSS 16. Differences between women attending public and private facilities were assessed using the Chi-squared test and uni variate analysis were performed.

Results: 474 women were recruited. The proportion of those with tertiary education using public facilities (69.6\%) was higher than in the private clinics (50.6\%) and they also belonged more to skilled/professional occupational group. Half of the women knew at least one obstetric danger sign. The percentage of women who knew at least four danger signs during pregnancy was more than 50\% and about $23.6 \%$ and $21.7 \%$ of them during delivery and after delivery respectively. A composite index of 12 indicators (BPCR Index) was computed yielding $44.15 \%$ without inclusion of the community component and $33.1 \%$ when the community component was included. Only $0.3 \%$ of respondents had knowledge of availability of community transport system.

Conclusions and Recommendation: The factors that affect BP/CR included the role of husbands, education level, parity. Non existence of community based support services for maternal health services was observed.

Improved education on BP/CR during antenatal visits is recommended and encouragement of greater community involvement.
\end{abstract}

\section{Introduction}

Every minute a woman dies during labor or delivery. The highest maternal mortality rates are in Africa, with a lifetime risk of 1 in 16; the lowest rates are in western nations (1:2400), with a global ratio of 400 maternal deaths per 100,000 live births ${ }^{1}$. "Every minute, the loss of a mother shatters a family and threatens the well-being of surviving children. For every woman who dies, 20 or more experience serious complications" These statements suggests that pregnancy and childbirth constitute a period of high risk of dying for women and therefore all efforts at saving a mother's life while she is trying to bring forth life is imperative.

Maternal mortality is a global public health challenge, with more than 500,000 women dying each year due to pregnancy and childbirth-related complications. Maternal mortality in Nigeria is second only to that of India. ${ }^{3}$ Nigeria accounts for only $2 \%$ of the world population but accounts for up to $10 \%$ of the maternal mortality rates. $^{4}$

Birth Preparedness and Complication Readiness (BPCR) is a key strategy in safe motherhood programmes, the elements of birth-preparedness and complication readiness has an association with increased use of a skilled provider at birth as well as in limiting undue delays. ${ }^{5,6,7}$ These key elements include recognition of danger signs, a plan for skilled birth attendant, a plan for the place of delivery, and saving money for transport or other costs, identification of a potential blood donor and assistant during labour. ${ }^{8,9}$ Birth Preparedness and Complication Readiness is a multi-level strategy. It can be explored at six levels- the individual pregnant woman, her family, her community, health facility, health service provider, and policy makers.Studies from Tanzania and Uganda amongst women however revealed that improved knowledge leads to better birth preparedness. ${ }^{10,11}$ BPCR has also led to enhanced utilization of skilled care and attendant reduction of maternal mortality, ${ }^{5,12}$

Nigeria is a leading contributor to the maternal death figure in sub-Saharan Africa not only because of the hugeness of her population but also because of her high maternal mortality ratio. ${ }^{13}$ As at 2008 , its maternal 
mortality ratio was 840 per 100,000 live births ${ }^{14}$ and the proportion of births attended by skilled health professional about $36 \% .{ }^{15}$ WHO recommends focused antenatal care and which requires individual health education on BPCR as one of its pillars. ${ }^{16}$ However preliminary enquiries from this locality reveal that FANC and BPCR counseling is not yet operational in Nigeria and this area. Awareness of the danger signs of obstetric complications among pregnant women and in their communities is the first step to early decision making and accepting appropriate and timely referral to essential obstetric and newborn care, thus, reducing the first and second phases of delay that lead to maternal mortality. ${ }^{17,18,19}$

This study therefore is a needs assessment designed to determine the level of awareness, attitude and behavior of women to birth preparedness, as well as their readiness for unforeseen complications.

\section{Methodology}

A descriptive cross sectional study in which multi stage sampling technique was utilized. There are 33 public health care providers comprising 1 Tertiary, 2 secondary and 30 primary health care facilities and 65 private health care facilities. FMC Umuahia was selected to represent public facilities. From 45 private health providers rendering maternal health services, 4 were selected by simple random sampling. Systematic random sampling of ANC clients was done to recruit participants at the selected sites, Interviewer administered prototype questionnaires were used to obtain data from antenatal attendees. Spontaneous responses were accepted for knowledge of danger signs and the 3 key danger signs during pregnancy include: severe vaginal bleeding, swollen hands/face, blurred vision. The 4 key danger signs during labor and childbirth include: Severe vaginal bleeding, Prolonged labor (> 12 hours), convulsions, retained placenta. The 3 key danger signs during the postpartum period include: severe vaginal bleeding, foul-smelling vaginal discharge, high fever. The 4 key danger signs in the newborn include: Convulsions/spasms/rigidity, difficult/fast breathing, very small baby, lethargy/unconsciousness Eligibility criteria: Consenting patients attending Antenatal clinics who fell within the systematic random sample while those who failed to give consent, morbidly ill or mentally unstable patients were excluded.

Ethical clearance was obtained from the research and ethics committee of FMC Umuahia and individual informed consent forms were signed by all the respondents.

Sample size determination: The sample size calculated with formula for comparison of a group to give a sample size of 384 with an anticipated non response rate of $20 \%$, the minimum sample size was estimated at 461 , However 474 respondents participated. 237 patients from private facilities and 237 respondents from the selected public facility respectively were interviewed.

Data analysis: Interviewer administration of questionnaires was done and data was thereafter cleaned and entered and analyzed with Epi info 7 software. Chi squared tests were done to test for any statistically significant differences at $95 \%$ confidence interval and at p value of 0.05 and uni variate analysis were performed.

Table 1: Socio demographic characteristics of respondents

\begin{tabular}{|l|l|l|}
\hline Variable & Number $(\mathrm{N}=474)$ & Percent $(\%)$ \\
\hline Age group & & \\
$<20$ & 13 & 2.74 \\
$20-24$ & 80 & 16.88 \\
$25-29$ & 189 & 39.87 \\
$30-34$ & 158 & 33.33 \\
35 and above & 34 & 7.17 \\
\hline Marital status & & \\
Single & 15 & 3.16 \\
Married & 452 & 95.36 \\
Separated & 6 & 1.27 \\
Living with partner & 1 & 0.21 \\
\hline Highest education & & \\
Nil & 4 & 0.84 \\
Primary & 6 & 1.27 \\
Secondary & 179 & 37.76 \\
Tertiary & 285 & 60.13 \\
\hline Parity & & \\
1 & 150 & 31.65 \\
$2-4$ & 204 & 43.03 \\
$>4$ & 120 & 25.32 \\
\hline
\end{tabular}


Highest number of respondents were found in 25-29years age bracket with 189(39.87\%), The least number of respondents was observed to be less than 20years old. 452 (95.36\%) of the respondents were married and 285 $(60.13 \%)$ had attained up to tertiary level of education

Table 2: Decision on when to start and where to attend ANC

\begin{tabular}{|c|c|c|c|c|}
\hline \multirow[t]{2}{*}{ Variable } & \multicolumn{2}{|c|}{ When to start ANC } & \multicolumn{2}{|l|}{ Where to attend } \\
\hline & Frequency $(\mathrm{N})$ & Percentage (\%) & Frequency $(\mathrm{N})$ & Percentage (\%) \\
\hline Husband & 76 & 16 & 102 & 21.5 \\
\hline Relation & 2 & 0.4 & 2 & 0.4 \\
\hline Self & 162 & 34.2 & 124 & 26.2 \\
\hline Self/Husband Jointly & 234 & 49.4 & 246 & 51.9 \\
\hline
\end{tabular}

The husband's influence on when to start and where to start ANC was greater than $65.4 \%$ and $73.4 \%$.

Table 3: Funding for ANC

\begin{tabular}{|l|l|l|}
\hline Variable & Frquency $(\mathrm{N})$ & Percentage $(\%)$ \\
\hline SELF & 30 & 6.2 \\
\hline HUSBAND & 432 & 91.2 \\
\hline RELATION & 10 & 2.2 \\
\hline HEALTH INSURANCE & 1 & 0.2 \\
\hline FREE & 1 & 0.2 \\
\hline
\end{tabular}

T he husband's funding for ANC was as high as $91.2 \%$.

Table 4: Knowledge of key danger signs

\begin{tabular}{|l|c|l|}
\hline Variable & Number (474) & Percent (\%) \\
\hline $\begin{array}{l}\text { Knowledge of at least three key } \\
\text { danger signs during pregnancy }\end{array}$ & 73 & 15.40 \\
\hline $\begin{array}{l}\text { Knowledge of at least four key } \\
\text { danger signs in/during labour }\end{array}$ & 93 & 19.62 \\
\hline $\begin{array}{l}\text { Knowledge of at least three key } \\
\text { danger signs post partum }\end{array}$ & 103 & 21.73 \\
\hline $\begin{array}{l}\text { Knowledge of at least four key } \\
\text { danger signs in the neonate }\end{array}$ & 63 & 13.30 \\
\hline
\end{tabular}

Knowledge of key danger signs was generally poor amongst these respondents in this study. The best appreciated was the knowledge of danger signs post partum at $21.73 \%$ whereas the poorest knowledge was that of danger signs in the neonate which was as low as $13.3 \%$.

Table 5: Number of ANC visits versus knowledge of danger signs

\begin{tabular}{|l|l|l|l|}
\hline $\begin{array}{l}\text { Knowledge of danger } \\
\text { sign }\end{array}$ & $\begin{array}{l}\text { Greater than four } \\
\text { ANC Visits } \\
\mathrm{N}=306(\%)\end{array}$ & $\begin{array}{l}\text { Less than four ANC Visits } \\
\mathrm{N}=106(\%)\end{array}$ & Chi square ( P value) \\
\hline During pregnancy & $42(13.7)$ & $30(17.9)$ & $1.45(0.23)$ \\
\hline Labour/delivery & $78(22.5)$ & $36(21.4)$ & $0.9(0.32)$ \\
\hline Post partum & $69(22.5)$ & $33(19.6)$ & $0.5(0.46)$ \\
\hline In Neonate & $45(14)$ & $18(10.7)$ & $0.5(0.02)^{*}$ \\
\hline
\end{tabular}

*statistically significant

The knowledge of key danger signs did not correlate with the number of ANC visits, there was no statistically significant difference in knowledge between the respondents who had attended more than 4 ANC visits when compared with those with fewer visits except in key danger signs in their neonate with $\mathrm{X}^{2}$ ( $\mathrm{p}$ value) of $0.5(0.02)$

Table 6: Parity versus knowledge of key danger signs

\begin{tabular}{|l|l|l|l|}
\hline $\begin{array}{l}\text { Knowledge of at least } \\
\text { one danger sign }\end{array}$ & Primip N=150(\%) & $\begin{array}{l}\text { Parity of } 2 \text { and above. N= } \\
324(\%)\end{array}$ & Chi square ( P value) \\
\hline During pregnancy & $21(14.0)$ & $54(16.7)$ & $0.54(0.45)$ \\
\hline Labour/delivery & $21(14.0)$ & $84(26)$ & $8.45(0.004)^{*}$ \\
\hline Post partum & $15(10)$ & $66(20.4)$ & $7.7(0.005)^{*}$ \\
\hline In Neonate & $12(8)$ & $54(16.7)$ & $6.42(0.01)^{*}$ \\
\hline
\end{tabular}


*statistically significant

There was statistically significant appreciation in the knowledge of at least one danger sign amongst women who had 2 or more pregnancies. There was no statistically significant difference in knowledge of danger signs during pregnancy between the primips and those who had experienced more than one pregnancy.

Table 7: Computation of BPCR INDEX

\begin{tabular}{|c|c|c|}
\hline Variable & Number (474) & Percent (\%) \\
\hline $\begin{array}{l}\text { Knowledge of danger signs } \\
\text { At least } 3 \text { in pregnancy } \\
\text { At least } 4 \text { in labour } \\
\text { At least } 3 \text { in Post partum } \\
\text { At least } 4 \text { in Neonate }\end{array}$ & $\begin{array}{l}73 \\
112 \\
103 \\
62\end{array}$ & $\begin{array}{l}15.4 \\
23.65 \\
21.75 \\
13.05\end{array}$ \\
\hline $\begin{array}{l}\text { Service use and planning actions: } \\
\text { Intentions and behaviors } \\
\text { To attend at least } 4 \text { ANC } \\
\text { To attend } 1^{\text {st }} \text { ANC in } 1^{\text {st }} \text { trimester } \\
\text { To give birth with SBA } \\
\text { To save money for delivery } \\
\text { To identify a transport mode }\end{array}$ & $\begin{array}{l}306 \\
200 \\
474 \\
294 \\
257\end{array}$ & $\begin{array}{l}645 \\
42.2 \\
100 \\
62.05 \\
54.2\end{array}$ \\
\hline $\begin{array}{l}\text { Knowledge of community resources } \\
\text { Community blood donation scheme } \\
\text { Community financial support system } \\
\text { Community transportation system }\end{array}$ & $\begin{array}{l}0 \\
0 \\
2\end{array}$ & $\begin{array}{l}0 \\
0 \\
0.42\end{array}$ \\
\hline Total & & 397.2 \\
\hline Average & & 33.1 \\
\hline $\begin{array}{lll}\begin{array}{l}\text { Average } \\
\text { component }\end{array} & \text { without } & \text { community } \\
\end{array}$ & & 44.15 \\
\hline
\end{tabular}

\section{Discussions}

The importance of goal oriented intervention of focused antenatal care with birth preparedness and complication readiness education as its bedrock cannot be overemphasized. ${ }^{20}$ The traditional ANC approach is based on risk assessment while it is an established fact that obstetric complications are not always predictable. Majority of the respondents were between 25-34years. More than half of the clients in both private and public hospitals had attained tertiary level of education. Only $1.3 \%$ of the clients received only primary education. In this study, more than half of the respondents knew at least one danger sign the awareness of danger signs. Better education is associated with better awareness of obstetric danger signs. Studies from Tanzania and Burkina Faso where the women had lower educational status also recorded lower knowledge of key danger signs. ${ }^{10,21}$ The attendance of ANC was higher in this study than in studies where it was discovered that women with lower educational status were less likely to attend ANC and consequently utilize skilled birth attendance. ${ }^{22,23}$ The number of antenatal visits however did not have the desired effect on knowledge of the key danger signs except in knowledge of danger signs in the neonate, This could be due to the fact the health talks given during the ANC visits focuses more on care of the neonate while ignoring the things expected to happen during pregnancy, childbirth and peuperium. This relationship was earlier established in a previous study conducted in Rufji which revealed that traditional ANC attendance had no significant effect on compliance to education and birth outcome. ${ }^{24}$ For this study, a composite index of 12 indicators (BPCR Index) was computed yielding $44.15 \%$ without inclusion of the community component and $33.1 \%$ when the community component was included. Only $0.3 \%$ of respondents had knowledge of availability of community transport system. Community support systems for the reduction of maternal mortality in this study area are almost nonexistent but this could be due to the fact that the study population is based in a predominantly urban setting where communal effort is not recognized and practiced. Finally the awareness and practice of the concept of birth preparedness and complication readiness in this study was low as witnessed from the BPCR Index obtained.

\section{Conclusions and Recommendation}

The factors that affect BP/CR included the role of husbands, level of education, parity and non existence of community based support services for maternal health services was observed. High ANC attendance did not yield corresponding high BPCR knowledge and actions therefore the content of the ANC 
visits needs to be reviewed. Improved education/counseling on BP/CR during antenatal visits is also recommended as well as encouragement of greater community involvement.

\section{References}

[1] Make every mother and child count. The World Health Report, 2005. Geneva, Switzerland: WHO 2005.

[2] WHO, UNICEF and UNFPA, Maternal mortality in 2000: estimates developed by WHO, UNICEF and UNFPA. Geneva, 2004.

[3] Christopher P, Lale S, Omar G, Katja I, Angela H. Maternal Mortality Declining in Middle-income Countries: http://www.un.org.kg/en/news-center/news-releases/article/news-center/69-unfpa/1567-maternal-mortality-declining-in-middleincome-countries accessed 1st May 2009

[4] Federal Ministry of Health (FMOH) [Nigeria] Road map for accelerating the attainment of the millennium development goals related to maternal and newborn health in Nigeria. Abuja, FMOH; 2005. 38) Gill K, Pande R, Malhotra A. Women deliver for development. The Lancet, 2007; 370: 1347-1357.

[5] McPherson RA, Khadka N, Moore JM, Sharma M: Are birth-preparedness programmes effective? Results from a field trial in Siraha district, Nepal. Journal of Health Population and Nutrition 2006, 24(4):479-88.

[6] Stanton C, Blanc AK, Croft T, Choi Y: Skilled care at birth in the developing world: progress to date and strategies for expanding coverage. J Biosoc Sci 2007; 39:109-120.

[7] Yanagisawa S, Oum S, Wakai S: Determinants of skilled birth attendance in rural Cambodia. Trop Med Int Health 2006, 11(2):23851.

[8] JHPIEGO. Maternal and Neonatal health (MNH) Program: Birth preparedness and complication readiness. A matrix of shared responsibilities. Maternal and Neonatal Health 2001, 23-31.

[9] Kaye D, Mirembe F, Aziga F, Namulema B: Maternal mortality and associated near-misses among emergency intrapartum obstetric referrals in Mulago Hospital, Kampala, Uganda. East African Medical Journal 2003, 80(3):144-9

[10] Pembe AB, Urassa DP, Carlstedt A, Lindmark G, Nystrom L, Darj E. Rural Tanzanian women's awareness of danger signs of obstetric complications. BMC Pregnancy Childbirth. 2009; 9:12.

[11] Kabakyenga JK, Östergren PO, Turyakira E, Pettersson KO. Knowledge of obstetric danger signs and birth preparedness practices among women in rural Uganda. Reprod Health. 2011; 16(8):33.

[12] Magoma M, Requejo J, Campbell OMR, Cousens S, Filippi V. High ANC coverage and low skilled attendance in a rural Tanzanian district: a case for implementing a birth plan intervention. BMC Pregnancy and Childbirth 2010; 10:13

[13] Hill K, Thomas K, AbouZahr C, Walker N, Say L, Inoue M, Suzuki E. Estimates of maternal mortality worldwide between 1990 and 2005: an assessment of available data. Lancet. 2007; 370(9595):1311-1319.

[14] Trends in maternal mortality: 1990 to 2008. Estimates developed by WHO, UNICEF, UNFPA and The World Bank. Available from http://www.childinfo.org/files/trends in maternal mortality 1990 to 2008. Accesed $10^{\text {th }}$ January 2012.

[15] 2010 MDG Report Nigeria available from www.mdgs.gov.ng accessed 1oth January 2012

[16] World Health Organization. Birth and emergency preparedness in antenatal care.

[17] Standards for maternal and neonatal care available from WHO .www.who.int/making-pregnancy safer/publications/. Accessed $12^{\text {th }}$ February 2012. )

[18] Thaddeus S, Maine D, Too far to walk: maternal mortality in context. Social Science and Medicine, 1994; $38: 1091$

[19] Killewo J, Anwar I, Bashir I, Yunus M, Chakraborty J. Perceived delay in healthcare-seeking for episodes of serious illness and its implications for safe motherhood interventions in rural Bangladesh. J Health Popul Nutr, 2006; 24(4): 403-13.

[20] The change project. Maternal Survival toolkits. 2004 available from www.change project.org/technical/maternaltoolkit.html. Accessed $10^{\text {th }}$ April 2009

[21] Maternal Neonatal Health: Focused Antenatal Care: Planning and Providing Care During Pregnancy. Program Brief March 2004

[22] Allisyn C. Moran, Gabriel S, Dineen R, Rawlin B, Yaméogo M, and Baya B. Birth-Preparedness for Maternal Health: Findings from Koupéla District, Burkina Faso. Journal of health, population and nutrition. 2006, Dec;24(4):489-497

[23] Jimogh A , Utilization of Antenatal services at the provincial hospital Mongomo, Guinea Equitoria. 2003 African Journal of Reproductive health 7(3):49-54.

[24] Van Eijk M, Bles M, Odhiambo F ,Use of antenatal services and delivery care among women in rural western Kenya: a community based survey : Reproductive Health, 2006

[25] Urassa DP, Carlstedt A, Nystrom L, Massawe SN, Lindmark G. Are process indicators adequate to assess essential obstetric care at district level? - a case study from Rufiji district, Tanzania. Afr J Reprod Health 2005, 9(3):100-11. 12. ) 